\title{
SỰ HIỆN DIỆN CỦA MỘT SỐ GENE BETA-LACTAMASE VÀ SỰ ĐỀ KHÁNG KHÁNG SINH CỦA VI KHUẪN ENTEROHEMORRHAGIC Escherichia coli VÀ ENTEROTOXIGENIC Escherichia coli PHÂN LẬP TỬ BÒ TẠI TỈNH BẾN TRE
}

\author{
Nguyễn Khánh Thuận*, Võ Thị Thanh Tiền, Trần Ngọc Bích và Lý Thị Liên Khai \\ Bộ môn Thú y, Khoa Nông nghiệp, Trường Đại học Cần Tho \\ *Ngưòi chịu trách nhiệm về bài viết: Nguyễn Khánh Thuận (email: nkthuan@ctu.edu.vn)
}

\section{Thông tin chung:}

Ngày nhận bài: $15 / 07 / 2021$

Ngày nhận bài sủa: 22/08/2021

Ngày duyệt đăng: 25/12/2021

\section{Title:}

Prevalence of beta-lactamase genes and antibiotic

resistance of

Enterohemorrhagic

Escherichia coli and

Enterotoxigenic Escherichia coli isolated from cattle in Ben Tre province

\section{Tù khóa:}

Bến Tre, đề kháng kháng sinh, EHEC, ETEC, gene beta-

lactamase

\section{Keywords:}

Antibiotic resistance, Ben Tre, beta-lactamase gene, EHEC, ETEC

\begin{abstract}
The survey was carried out to determine the antibiotic resistance and prevalence rate of beta-lactamase genes in 21 Enterohemorrhagic Escherichia coli (EHEC) strains and 38 Enterotoxigenic Escherichia coli (ETEC)strains isolated from cattle in Ben Tre province. The EHEC strains showed the high resistance rate against colistin (71.43\%) and ampicillin (61.90\%), however, they still were significantly sensitive to doxycycline (100.00\%), amikacin (95.24\%). Among 14 multi-drug resistance patterns in EHEC, the popular pattern was $\mathrm{Cz}+\mathrm{Co}(9.52 \%)$. Of ETEC strains, those strains showed high sensitivity to the examined antibiotics, $100 \%$ strains exhibited the sensitivity to gentamicin, amikacin, levofloxacin, and ofloxacin (100\%). Among of 13 multidrug resistance patterns in ETEC, the pattern of $\mathrm{Am}+\mathrm{Ac}+\mathrm{Sm}$ and $\mathrm{Am}+\mathrm{Cu}+\mathrm{Co}$ were present at the high rate (5.26\%). The PCR results indicated that EHEC and ETEC strains harbored $4 / 5$ beta-lactamase genes examined. The blaampC gene was detected at the highest rate in EHEC, ETEC with $57.14 \%, 42.11 \%$ respectively. The blaCMY gene was not found in both two groups. There were three combination patterns of beta-lactamase genes, the pattern of blaampC+blaTEM was the most recorded (10.17\%).
\end{abstract}

\section{TÓM TẮT}

Nghiên cứu được thưc hiện nhằm khảo sát sư đề kháng kháng sinh và tỷ lệ hiện diện gene mã hoá beta-lactamase trên 21 chüng Enterohemorrhagic Escherichia coli (EHEC) và 38 chủng Enterotoxigenic Escherichia coli (ETEC) phân lập tù bò tại tỉnh Bến Tre. Các chủng EHEC có tỷ lệ đề kháng cao vói colistin $(71,43 \%)$ và ampicillin $(61,90 \%)$, nhưng còn tỷ lệ nhay cám rất cao với doxycycline (100,00\%), amikacin $(95,24 \%)$. Trong 14 kiểu hình đa kháng của các chủng EHEC, phổ biến là kiểu hình $C z+C o(9,52 \%)$. Đối với ETEC, các chủng này còn nhạy cảm cao với các loại kháng sinh, nhay cảm $100 \%$ đối với gentamicin, amikacin, levofloxacin và ofloxacin. Trong 13 kiểu hìn đa kháng của các chủng ETEC, kiểu hình $\mathrm{Am}+\mathrm{Ac}+\mathrm{Sm}$ và $\mathrm{Am}+\mathrm{Cu}+\mathrm{Co}$ xuất hiện phổ biến $(5,26 \%)$. Khảo sát bằng phương pháp PCR cho thấy trên các chủng EHEC và ETEC có sụ hiện diện của $4 / 5$ gene beta-lactamase được khảo sát. Gene blaampC chiếm tỷ lệ cao nhất trên EHEC, ETEC vói tỷ lẹ lần luợt là $57,14 \%, 42,11 \%$. Không có sự hiện diện của gene blaCMY trên cả hai chủng. Có sự hình thành 3 kiểu hình kết hợp gene beta-lactamse, trong đó kiểu hình blaampC+blaTEM được ghi nhận nhiều nhất $(10,17 \%)$. 


\section{GIỚI THIỆ}

Trong quá trình chăn nuôi, việc thường xuyên sử dụng kháng sinh để phòng và điều trị bệnh do vi khuẩn gây ra nhưng không tuân thủ các quy định an toàn dẫn đến sự hình thành nhiều chủng đề kháng kháng sinh. Tình trạng gia tăng sự đề kháng hay đa kháng của vi khuẩn Gram âm, đặc biệt là họ vi khuẩn đường ruột Enterobacteriaceae đang là vấn đề toàn cầu (Partridge, 2011). Trong đó, Escherichia coli là vi khuẩn có khả năng đề kháng rất cao với nhiều loại kháng sinh, bao gồm các kháng sinh nhóm beta-lactam. Có nhiều cơ chế kháng kháng sinh, trong đó cơ chế ức chế bằng enzyme betalactamase phổ rộng - ESBL (Extended - Spectrum Beta -Lactamases) đối với các kháng sinh nhóm beta-lactam là cơ chế thường gặp. $\mathrm{ESBL}$ thường được tìm thấy trên nhóm Enterobacteriaceae, nhất là trên E. coli (Bradford, 2001; Paterson \& Bonomo, 2005). Các gene mã hóa cho enzyme nhóm này (TEM, SHV, $\mathrm{ampC}, \mathrm{CMY}, \mathrm{CTX} . .$.$) thường nằm$ trên plasmid, một số gene nằm trên transpose, integrin hoặc nhiễm sắc thể. Do đó, các gene kháng kháng sinh có thể lan truyền trong cùng loài hoặc cho các loài vi khuẩn gây bệnh khác như Salmonella, Shigella... làm gia tăng tình trạng kháng kháng sinh trong chăn nuôi (Carattoli, 2009; Paterson \& Bonomo, 2005). Ngoài ra, trong các nhóm vi khuẩn $E$. coli, Enterohemorrhagic Escherichia coli (EHEC) và Enterotoxigenic Escherichia coli (ETEC) thường hiện diện trên đàn bò và có khả năng gây bệnh cho vật nuôi, cũng nhu lây nguy hiểm cho sức khoẻ con người.

Một số nghiên cứu trong và ngoài nước đã ghi nhận sự đề kháng kháng sinh cao trên các chủng EHEC và ETEC. Bùi Thị Ba và ctv. (2012) đã xác định một số gene ESBL của vi khuẩn EHEC O157:H7 phân lập từ trâu bò khỏe mạnh tại Nam Trung bộ; trong đó, cao nhất là gene blaTEM $(64,70 \%)$, blaSHV và blaCMY $(11,76 \%)$. Nguyễn Xuân Hòa và ctv. (2020) khảo sát trên bê tại huyện Đức Trọng, tỉnh Lâm Đồng đã phân lập được vi khuẩn ETEC đề kháng cao với amoxicillin, doxycyclin, oxytetracyclin với tỷ lệ lần lượt là $50 \%$, $70 \%$ và $90 \%$. Tại Trung Quốc, Ali et al. (2016) đã ghi nhận trên đàn bò sữa thương phẩm có sự hiện diện của $E$. coli sinh ESBL đa kháng thuốc, các chủng phân lập đề kháng đối với ampicillin (88,89\%), amoxicillin/clavulanic acid $(75,00 \%)$, chloramphenicol $(52,78 \%)$, ciprofloxacin $(44,44 \%)$, gentamicin $(72,22 \%)$, nalidixic acid $(80,56 \%)$, tetracycline và trimethoprim/sulphamethoxazole (75\%). Montso et al. (2019) khi nghiên cứu về đặc điểm của $E$. coli ESBL phân lập từ phân và thịt bò tại Nam Phi đã cho thấy chúng đề kháng với amoxicillin, aztreonam, ceftazidime, cefotaxime và piperacillin; đồng thời, các gene blaTEM, blaSHV và blaCTX-M được phát hiện với tỷ lệ tương ứng là $85,5 \%, 69,6 \%$ và $58 \%$.

Tại Đồng bằng sông Cửu Long, Bến Tre có điều kiện thuận lợi phát triển chăn nuôi bò và được chọn là hình thức chăn nuôi chính giúp người dân xóa đói giảm nghèo. Tuy nhiên, điều kiện vệ sinh chăn nuôi còn rất hạn chế, cùng với việc sử dụng kháng sinh trong phòng và điều trị bệnh cho bò chưa được kiểm soát chặt chẽ, dẫn đến nguy cơ xuất hiện hiện tượng đề kháng kháng sinh trên vi khuẩn tại đây. Do đó, nghiên cứu được thực hiện nhằm xác định thực trạng đề kháng kháng sinh và sự hiện diện của một số gene mã hóa beta-lactamase trên vi khuẩn EHEC và ETEC phân lập từ đàn bò tại đây; qua đó, cung cấp thông tin hữu ích cho việc quản lý và phòng trị bệnh do vi khuẩn $E$. coli gây ra trên bò tại tỉnh Bến Tre.

\section{VẠT LIẾU VÀ PHƯƠNG PHÁP NGHIẾN CÚU}

\subsection{Vật liệu nghiên cứu}

Tổng số 59 chủng vi khuẩn bao gồm EHEC $(\mathrm{n}=$ 21) và $\mathrm{ETEC}(\mathrm{n}=38)$ được phân lập từ phân trên đàn bò thịt tại tỉnh Bến Tre từ tháng 10/2020 đến $12 / 2020$ được sử dụng trong nghiên cứu này. Các chủng này được phân lập và bảo quản tại phòng Thí nghiệm Thú $\mathrm{Y}$ chuyên ngành 2 , Bộ môn Thú Y, Khoa Nông nghiệp, Trường Đại học Cần Thơ.

\subsection{Phương pháp nghiên cứu}

2.2.1. Phuoong pháp kiểm tra sư đề kháng của vi khuẩn EHEC và ETEC đối với kháng sinh

Vi khuẩn EHEC và ETEC được xác định sự đề kháng đối với 13 loại kháng sinh. Phương pháp khuếch tán trên đĩa thạch Mueller-Hinton (MHA, Merck, Đức) được sử dụng trong nghiên cứu này (Bauer et al., 1966). Canh khuẩn EHEC và ETEC được chuẩn độ với dung dịch chuẩn McFarland 0,5 $\left(10^{8} \mathrm{CFU} / \mathrm{mL}\right)$ trước khi được chang lên đĩa MHA. Sau khi đặt đĩa kháng sinh chuẩn và ủ ở $37^{\circ} \mathrm{C}$ trong 24 giờ, kết quả xác định mức độ nhạy cảm hay đề kháng của các chủng EHEC và ETEC đối với kháng sinh dựa theo tiêu chuẩn của Viện Tiêu chuẩn lâm sàng và xét nghiệm (Clinical and Laboratory Standards Institute-CLSI, 2019).

Các đĩa kháng sinh chuẩn được cung cấp bởi Công ty Nam Khoa Biotek (thành phố Hồ Chí Minh) dùng trong nghiên cứu này bao gồm: ampicillin 
(Am) $10 \mu \mathrm{g}$, amoxicillin/clavulanic acid (Ac) 20/10 $\mu \mathrm{g}$, ceftazidime $(\mathrm{Cz}) 30 \mu \mathrm{g}$, cefuroxime $(\mathrm{Cu}) 30 \mu \mathrm{g}$, colistin (Co) $10 \mu \mathrm{g}$, gentamicin (Ge) $10 \mu \mathrm{g}$, amikacin (Ak) $30 \mu \mathrm{g}$, streptomycin (Sm) $10 \mu \mathrm{g}$, tetracyline (Te) $30 \mu \mathrm{g}$, doxycyline (Dx) $30 \mu \mathrm{g}$, chloramphenicol (Cl) $30 \mu \mathrm{g}$, levofloxacin (Lv) $5 \mu \mathrm{g}$, ofloxacin (Of) $5 \mu \mathrm{g}$.

\subsubsection{Phuoong pháp xác định sụ hiện diện của môt số gene mã hóa beta-lactamase trên các chủng EHEC và ETEC}

Các chủng vi khuẩn EHEC và $\mathrm{ETEC}$ được $\mathrm{ly}$ trích DNA bằng phương pháp sốc nhiệt của Soumet et al. (1994). Bộ kit Bioline MyTaq Mix 2X-New Generation (Meridian Bioscience, Mỹ) được sử dụng trong nghiên cứu này. Hỗn hợp cho một phản ứng PCR $(25,0 \mu \mathrm{L})$ bao gồm Master Mix $2 X(12,5$ $\mu \mathrm{L}$ ); đoạn mồi xuôi và mồi ngược với nồng độ 10 $\mu \mathrm{M}(0,5 \mu \mathrm{L} /$ đoạn $)$; nước cất tinh khiết $(9,5 \mu \mathrm{L})$ và DNA khuôn mẫu $(2,0 \mu \mathrm{L})$.

Chu trình nhiệt cho phản ứng PCR được sử dụng để xác định sự hiện diện của một số gene betalactamase như sau: tiền biến tính $\left(95^{\circ} \mathrm{C}, 5\right.$ phút $) ; 35$ chu kỳ: biến tính $\left(95^{\circ} \mathrm{C}, 1\right.$ phút), gắn mồi $\left(55-58^{\circ} \mathrm{C}\right.$, 1 phút), kéo dài $\left(72^{\circ} \mathrm{C}, 1\right.$ phút); kết thúc $\left(72^{\circ} \mathrm{C}, 10\right.$ phút). Sản phẩm PCR được điện di ở hiệu điện thế $100 \mathrm{~V}$ trong 30 phút trên gel 1,5\% agarose và được nhuộm với dung dịch ethidium bromide; đọc kết quả bằng cách quan sát và chụp ảnh gel dưới ánh sáng UV.

Trình tự nucleotide của các đoạn mồi xác định gene mã hóa beta-lactamase được sử dụng trong nghiên cứu này thể hiện qua Bảng 1 .

Bảng 1. Trình tự nucleotide các đoạn mồi xác định gene beta-lactamase trên vi khuẩn EHEC và ETEC

\begin{tabular}{|c|c|c|c|}
\hline Primer & Trình tự primer (5'- 3') & Kích thước (bp) & Tài liệu tham khảo \\
\hline blaTEM-F & ATTCTTGAAGACGAAAGGGC & \multirow{2}{*}{1,150} & \multirow{2}{*}{ Jouini et al., 2007} \\
\hline blaTEM-R & ACGCTCAGTGGAACGAAAAC & & \\
\hline blaampC-F & AATGGGTTTTCTACGGTCTG & \multirow{2}{*}{191} & \multirow{2}{*}{ Caroff et al., 1999} \\
\hline blaampC-R & GGGCAGCAAATGTGGAGCAA & & \\
\hline blaSHV-F & TCGCCTCGTGTATTATCTCCC & \multirow{2}{*}{768} & \multirow{2}{*}{ Van et al., 2008} \\
\hline blaSHV-R & CGCAGATAAATCACCACAATG & & \\
\hline blaCMY-F & ATGATGAAAAAATCGTTATGC & \multirow{2}{*}{507} & \multirow{2}{*}{ Eckert et al., 2004} \\
\hline blaCMY-R & TTGTAGCTTTTCAAGAATGCGC & & \\
\hline blaCTX-M1-F & TTAGGAARTGTGCCGCTGYA & \multirow{2}{*}{688} & \multirow{2}{*}{ Dallenne et al., 2010} \\
\hline blaCTX-M1-R & CGATATCGTTGGTGGTRCCAT & & \\
\hline
\end{tabular}

$F$ : forward (mồi xuôi), R: reverse (mồi ngược)

\subsection{Phương pháp xử lý số liệu}

Kết quả khảo sát được phân tích thống kê bằng phương pháp Chi bình phương, Fisher's exact test với độ tin cậy $95 \%$ trên phần mềm Minitab 16.

\section{KẾT QUẢ VÀ THẢO LUẬN}

\subsection{Kết quả xác định sự đề kháng đối với kháng sinh của vi khuẩn EHEC và ETEC}

\subsubsection{Sự đề kháng kháng sinh của vi khuẩn EHEC phân lạp trên bò}

Kết quả khảo sát cho thấy các chủng vi khuẩn EHEC còn nhạy cảm với 11/13 loại kháng sinh được khảo sát. Tuy nhiên, các chủng EHEC đã có tỷ lệ đề kháng khá cao với colistin và ampicillin với tỷ lệ lần lượt là $71,43 \%$ và $61,90 \%$ (Bảng 2 ). Sự đề kháng của vi khuẩn $E$. coli đối với colistin chỉ là $22,2 \%$ trên gà và $22,4 \%$ trên heo khi được ghi nhận tại Tiền Giang (Nguyen et al., 2016). Nghiên cứu của Nguyễn Khánh Thuận và Lý Thị Liên Khai (2020) trên tổng số 24 chủng EHEC O157:H7/H- phân lập trên bò tại Đồng bằng sông Cửu Long cho kết quả còn nhạy cảm cao $(100 \%)$ với 7 loại kháng sinh (ceftazidime, gentamicin , amikacin, kanamycin, tetracycline, ciprofloxacin, và norfloxacin); và các chủng này cho thấy có sự đề kháng khá cao đối với ampicillin (50,00\%). Iweriebor et al. (2015) cũng đã ghi nhận sự đề kháng kháng sinh của EHEC phân lập trền bò đối với chloramphenicol $(89,5 \%)$, ampicillin (94,74\%), tetracycline $(96,84 \%)$, oxytetracycline $(94,74 \%)$, cefuroxime $(82 \%)$. Trên bò, các chủng EHEC không gây ra bệnh cho vật chủ, nên kháng sinh thường không được dùng để điều trị EHEC (Armstrong et al., 1996). Tuy nhiên, các chủng $E$. coli có thể tiếp xúc với các vi sinh vật mang tính đề kháng kháng sinh trong hệ vi sinh vật đường ruột, từ đó, hình thành nên tính đề kháng (Poirel et al., 2018). Võ Văn Ninh (2001) cũng ghi nhận điều đáng lo ngại là vi khuẩn có thể đề kháng kháng sinh chéo với các kháng sinh trong nhóm và di truyền tính đề kháng từ một nhóm vi khuẩn này sang một nhóm hoặc loài vi khuẩn khác trong môi trường, đặc biệt giữa các vi khuẩn Gram âm. Do đó, vẫn còn tồn tại nguy cơ là các chủng EHEC dù chưa bao giờ tiếp xúc với kháng sinh nhưng có thể bị truyền tính đề kháng từ vi khuẩn khác sang hệ sinh vật đường ruột. 
Bảng 2. Tỷ lệ đề kháng kháng sinh của vi khuẩn EHEC phân lập trên bò tại tỉnh Bến Tre (n=21)

\begin{tabular}{lcrrrr}
\hline \multirow{2}{*}{ Kháng sinh } & \multirow{2}{*}{ Ký hiệu } & \multicolumn{2}{c}{ Nhạy } & \multicolumn{2}{c}{ Kháng } \\
\cline { 3 - 6 } & So & Só chủng & Tỷ lệ (\%) & Số chủng & Tỷ lệ (\%) \\
\hline Doxycycline & Do & 21 & 100,00 & 0 & 0,00 \\
Amikacin & $\mathrm{Ak}$ & 20 & 95,24 & 1 & 4,76 \\
Gentamicin & $\mathrm{Ge}$ & 19 & 90,48 & 2 & 9,52 \\
Levofloxacin & $\mathrm{Lv}$ & 19 & 90,48 & 2 & 9,52 \\
Ofloxacin & $\mathrm{Of}$ & 19 & 90,48 & 2 & 9,52 \\
Amoxicillin/clav. acid* & $\mathrm{Ac}$ & 17 & 80,95 & 4 & 19,05 \\
Cefuroxime & $\mathrm{Cu}$ & 16 & 76,19 & 5 & 23,81 \\
Chloramphenicol & $\mathrm{Cl}$ & 15 & 71,43 & 6 & 28,57 \\
Ceftazidime & $\mathrm{Cz}$ & 14 & 66,67 & 7 & 33,33 \\
Streptomycin & $\mathrm{Sm}$ & 11 & 52,38 & 10 & 47,62 \\
Tetracycline & $\mathrm{Te}$ & 11 & 52,38 & 10 & 47,62 \\
Ampicillin & $\mathrm{Am}$ & 8 & 38,10 & 13 & 61,90 \\
Colistin & $\mathrm{Co}$ & 6 & 28,57 & 15 & 71,43 \\
\hline
\end{tabular}

*amoxcillin/clavulanic acid

Kết quả phân tích cũng cho thấy $15 / 21$ chủng EHEC đa kháng với kháng sinh chiếm tỷ lệ cao $(71,43 \%)$. EHEC đa kháng từ 2 đến 8 loại kháng sinh với 14 kiểu hình đa kháng, và kiểu hình $\mathrm{Cz}+\mathrm{Co}$ xuất hiện nhiều với tỷ lệ là $9,52 \%$ (Bảng 3 ). Điều này cho thấy các chủng vi khuẩn EHEC này có khả năng biểu hiện tính đa kháng với nhiều loại kháng sinh. Những phân tích về mặt di truyền cần thực hiện thêm để xác định chính xác nguyên nhân dẫn đến sự đa kháng kháng sinh này. Mặt khác, hầu hết trong tất cả các kiểu hình đa kháng có sự hiện diện của ampicillin (13/14 kiểu hình) và colistin (11/14 kiểu hình). Điều này phù hợp với kết quả sự đề kháng cao của EHEC với hai loại kháng sinh này được thể hiện trong Bảng 2. Vi khuẩn hình thành sự đề kháng với kháng sinh thông qua đột biến hoặc thông qua việc thu nhận các gene kháng thuốc (Liu \& Pop, 2009).
Sự gia tăng kiểu đề kháng đa thuốc có thể là do sự tích tụ của các gene mã hóa cho sự kháng thuốc kháng sinh, trên nhiễm sắc thể của vi khuẩn hoặc plasmid (Yamamoto et al., 2013). Yamamoto et al. (2014) nghiên cứu tại 3 khu vực của Nhật Bản (Hokkaido, Chubu và Kyushu) cũng ghi nhận E. coli phân lập từ phân bò thịt đề kháng đồng thời từ 9-11 loại kháng sinh. Các kết quả trên cho thấy các chủng EHEC phân lập trên bò có khả năng đa kháng cao đối với kháng sinh, là yếu tố nguy cơ lớn trong điều trị đối với sức khoẻ con người nếu các chủng EHEC bị truyền lây sang người (Nguyen \& Sperandio, 2012). Đồng thời, sự đề kháng kháng sinh này của EHEC có thể trở thành nguy cơ phát tán các yếu tố di truyền đề kháng sang hệ vi sinh vật đường ruột ở bò.

Bảng 3. Kiểu hình đa kháng kháng sinh của vi khuẩn EHEC $(\mathrm{n}=21)$

\begin{tabular}{|c|c|c|c|c|}
\hline Số lượng kháng sinh & Kiểu hình đa kháng & Số kiểu đa kháng & Số chủng & Tỷ lệ (\%) \\
\hline 2 & $\mathrm{Cz}+\mathrm{Co}$ & 1 & 2 & 9,52 \\
\hline \multirow{2}{*}{3} & $\mathrm{Am}+\mathrm{Co}+\mathrm{Te}$ & \multirow{2}{*}{2} & 1 & 4,76 \\
\hline & $\mathrm{Am}+\mathrm{Cu}+\mathrm{Co}$ & & 1 & 4,76 \\
\hline \multirow{3}{*}{4} & $\mathrm{Am}+\mathrm{Co}+\mathrm{Te}+\mathrm{Cl}$ & \multirow{3}{*}{3} & 1 & 4,76 \\
\hline & $\mathrm{Am}+\mathrm{Cu}+\mathrm{Sm}+\mathrm{Te}$ & & 1 & 4,76 \\
\hline & $\mathrm{Am}+\mathrm{Ac}+\mathrm{Sm}+\mathrm{Te}$ & & 1 & 4,76 \\
\hline \multirow{2}{*}{5} & $\mathrm{Am}+\mathrm{Cz}+\mathrm{Co}+\mathrm{Sm}+\mathrm{Cl}$ & \multirow{2}{*}{2} & 1 & 4,76 \\
\hline & $\mathrm{Am}+\mathrm{Ac}+\mathrm{Co}+\mathrm{Ge}+\mathrm{Sm}$ & & 1 & 4,76 \\
\hline \multirow{4}{*}{6} & $\mathrm{Am}+\mathrm{Cz}+\mathrm{Cu}+\mathrm{Co}+\mathrm{Sm}+\mathrm{Te}$ & \multirow{4}{*}{4} & 1 & 4,76 \\
\hline & $\mathrm{Am}+\mathrm{Cz}+\mathrm{Cu}+\mathrm{Co}+\mathrm{Sm}+\mathrm{Cl}$ & & 1 & 4,76 \\
\hline & $\mathrm{Am}+\mathrm{Cz}+\mathrm{Co}+\mathrm{Sm}+\mathrm{Te}+\mathrm{Cl}$ & & 1 & 4,76 \\
\hline & $\mathrm{Am}+\mathrm{Cu}+\mathrm{Co}+\mathrm{Sm}+\mathrm{Te}+\mathrm{Cl}$ & & 1 & 4,76 \\
\hline 7 & $\mathrm{Am}+\mathrm{Ac}+\mathrm{Co}+\mathrm{Ak}+\mathrm{Te}+\mathrm{Lv}+\mathrm{Of}$ & 1 & 1 & 4,76 \\
\hline 8 & $\mathrm{Am}+\mathrm{Ac}+\mathrm{Ge}+\mathrm{Sm}+\mathrm{Te}+\mathrm{Cl}+\mathrm{Lv}+\mathrm{Of}$ & 1 & 1 & 4,76 \\
\hline Tổng & & 14 & 15 & 71,43 \\
\hline
\end{tabular}

Ac: amoxicillin/clavulanic acid; Am: ampicillin; Cz: ceftazidime; Cu: cefuroxime; Co: colistin;Ge: gentamicin; Te: tetracycline; Cl: chloramphenicol; Lv: levofloxacin; Sm: streptomycin; Of: ofloxacin 


\subsubsection{Sư đề kháng kháng sinh của vi khuẩn ETEC phân lạp trên bò}

Các chủng ETEC được kiểm tra sự đề kháng đối với 13 loại kháng sinh khảo sát. Kết quả được thể hiện qua Bảng 4.

Kết quả kiểm tra đã cho thấy vi khuẩn ETEC phân lập từ bò có tỷ lệ đề kháng thấp đối với 13 loại kháng sinh được khảo sát. Các chủng ETEC này còn nhạy cảm cao $(100,00 \%)$ với 4 loại kháng sinh gentamicin, amikacin, levofloxacin và ofloxacin (Bảng 4). Các chủng EHEC có khả năng gây bệnh đường tiêu hoá trên bò, tuy nhiên, khảo sát thực tế về tình trạng chăn nuôi trên địa bàn cho thấy đàn bò tại đây ít xuất hiện bệnh đường tiêu hóa. Đồng thời, việc sử dụng kháng sinh được hạn chế nhằm tránh ảnh hưởng đến hệ vi sinh vật tiêu hoá ở dạ cỏ. Do đó, đây có thể là nguyên nhân các chủng ETEC hiện diện trên đàn bò tại đây vẫn còn nhạy cảm cao với kháng sinh. Nguyễn Xuân Hòa và ctv. (2020) khảo sát trên bê tại huyện Đức Trọng, tỉnh Lâm Đồng để xác định vai trò gây bệnh và tính mẫn cảm kháng sinh của vi khuẩn ETEC. Kết quả cho thấy các chủng $E$. coli rất mẫn cảm với enrofloxacin $(90 \%)$, gentamicin $(80 \%)$ và ceftiofur $(80 \%)$. Trong khi đó, các chủng $E$. coli này lại đề kháng với amoxicillin, doxycyclin, oxytetracyclin với tỷ lệ lần lượt là $50 \%$, $70 \%$ và $90 \%$. Ibrahim et al. (2016) nghiên cứu trên các chủng $E$. coli phân lập từ bò sữa đã đề kháng từ 3 đến 15 loại kháng sinh, đề kháng cao nhất là với ampicillin $(56,3 \%)$, và thấp nhất với imipenem $(1,6 \%)$.

Bảng 4. Tỷ lệ đề kháng kháng sinh của vi khuẩn ETEC phân lập trên bò tại tỉnh Bến Tre (n=38)

\begin{tabular}{lcrrrr}
\hline \multirow{2}{*}{ Kháng sinh } & \multirow{2}{*}{ Ký hiệu } & \multicolumn{2}{c}{ Nhạy } & \multicolumn{3}{c}{ Kháng } \\
\cline { 3 - 6 } & Se & Tý chủng & Tệ (\%) & Số chủng & Tỷ lệ (\%) \\
\hline Gentamicin & $\mathrm{Am}$ & 38 & 100,00 & 0 & 0,00 \\
Amikacin & $\mathrm{Lv}$ & 38 & 100,00 & 0 & 0,00 \\
Levofloxacin & $\mathrm{Of}$ & 38 & 100,00 & 0 & 0,00 \\
Ofloxacin & $\mathrm{Dx}$ & 100,00 & 0 & 0,00 \\
Doxycycline & $\mathrm{Cz}$ & 37 & 97,37 & 1 & 2,63 \\
Ceftazidime & $\mathrm{Cu}$ & 34 & 92,11 & 3 & 7,89 \\
Cefuroxime & $\mathrm{Cl}$ & 34 & 89,47 & 4 & 10,53 \\
Chloramphenicol & $\mathrm{Co}$ & 33 & 89,47 & 4 & 10,53 \\
Colistin & $\mathrm{Ac}$ & 31 & 86,84 & 5 & 13,16 \\
Amoxcillin/clav.acid* & $\mathrm{Te}$ & 28 & 71,58 & 7 & 18,42 \\
Tetracycline & $\mathrm{Sm}$ & 27 & 73,68 & 10 & 26,32 \\
Streptomycin & $\mathrm{Am}$ & 26 & 68,42 & 11 & 28,95 \\
Ampicillin & & & & 12 & 31,58 \\
\hline
\end{tabular}

*amoxcillin/clavulanic acid

Bảng 5. Kiểu hình đa kháng kháng sinh của vi khuẩn ETEC (n=38)

\begin{tabular}{|c|c|c|c|c|}
\hline Số kháng sinh đa kháng & Kiểu hình đa kháng & Số kiểu đa kháng & Số chủng & Tỷ lệ (\%) \\
\hline \multirow[t]{3}{*}{ ( } & $\mathrm{Am}+\mathrm{Te}$ & \multirow{3}{*}{ (1) } & 1 & 2,63 \\
\hline & $\mathrm{Ac}+\mathrm{Cu}$ & & 1 & 2,63 \\
\hline & Te+Dx & & 1 & 2,63 \\
\hline \multirow{5}{*}{3} & $\mathrm{Am}+\mathrm{Ac}+\mathrm{Sm}$ & \multirow{5}{*}{5} & 2 & 5,26 \\
\hline & $\mathrm{Am}+\mathrm{Sm}+\mathrm{Te}$ & & 1 & 2,63 \\
\hline & $\mathrm{Am}+\mathrm{Cu}+\mathrm{Co}$ & & 2 & 5,26 \\
\hline & $\mathrm{Am}+\mathrm{Ac}+\mathrm{Sm}$ & & 1 & 2,63 \\
\hline & $\mathrm{Am}+\mathrm{Sm}+\mathrm{Cl}$ & & 1 & 2,63 \\
\hline \multirow{2}{*}{4} & $\mathrm{Ac}+\mathrm{Sm}+\mathrm{Te}+\mathrm{Cl}$ & \multirow{2}{*}{2} & 1 & 2,63 \\
\hline & $\mathrm{Am}+\mathrm{Ac}+\mathrm{Sm}+\mathrm{Te}$ & & 1 & 2,63 \\
\hline \multirow{2}{*}{5} & $\mathrm{Am}+\mathrm{Ac}+\mathrm{Sm}+\mathrm{Te}+\mathrm{Cl}$ & \multirow{2}{*}{2} & 1 & 2,63 \\
\hline & $\mathrm{Am}+\mathrm{Cz}+\mathrm{Co}+\mathrm{Sm}+\mathrm{Cl}$ & & 1 & 2,63 \\
\hline 6 & $\mathrm{Am}+\mathrm{Cz}+\mathrm{Cu}+\mathrm{Co}+\mathrm{Sm}+\mathrm{Te}$ & 1 & 1 & 2,63 \\
\hline Tổng & & 13 & 15 & 39,47 \\
\hline
\end{tabular}

Ac: amoxicillin/clavulanic acid; Am: ampicillin; Cz: ceftazidime; Cu: cefuroxime; Co: colistin; Te: tetracycline; Cl: chloramphenicol; Dx: doxycycline; Sm: streptomycin 
Mặc dù các chủng ETEC còn nhạy cảm cao đối với kháng sinh, nhưng kết quả phân tích cũng cho thấy có $15 / 38(39,47 \%)$ chủng vi khuẩn ETEC đa kháng từ 2 đến 6 loại kháng sinh với 13 loại kiểu hình đa kháng (Bảng 5). Trong đó, đa kháng 3 loại kháng sinh $(\mathrm{Am}+\mathrm{Ac}+\mathrm{Sm}, \mathrm{Am}+\mathrm{Cu}+\mathrm{Co})$ xuất hiện cao hơn $(5,26 \%)$. Đồng thời, tương tự như trên EHEC, ampicillin (Am) là kháng sinh có mặt nhiều nhất trong tất cả các kiểu hình đa kháng (11/13). Ampicillin cũng là kháng sinh có tỷ lệ đề kháng cao nhất $(31,58 \%)$ trên các chủng ETEC (Bảng 4). Nguyên nhân các chủng ETEC trên bò tại Bến Tre biểu hiện tính đa kháng với nhiều loại kháng sinh cần được tiếp tục nghiên cứu về mặt di truyền để xác định yếu tố quyết định tính đa kháng. Ball et al. (2019) phân lập E. coli trên bò tại Wakisa, Uganda cho thấy $21 \%$ các chủng này đã kháng với ít nhất
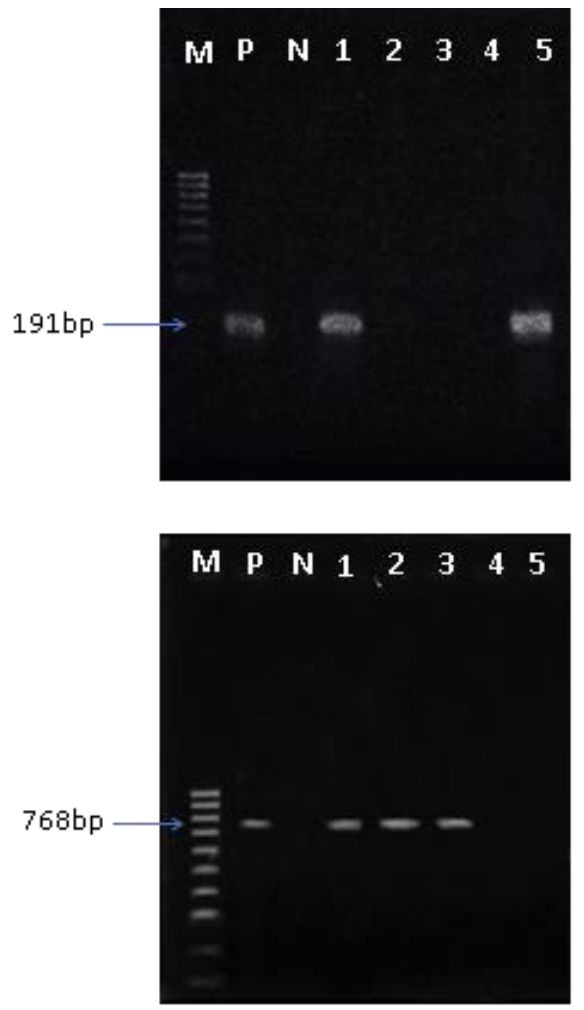

một loại kháng sinh và $7 \%$ biểu hiện kháng đa thuốc. Do đó, việc đưa ra các biện pháp kiểm soát hiệu quả việc sử dụng kháng sinh, cũng như ngăn ngừa sự phát tán của các chủng ETEC đề kháng kháng sinh ra môi trường và các loài động vật khác, cũng như vấy nhiễm sang người là cần thiết.

\subsection{Sự hiện diện của một số gene beta- lactamase trên các chủng EHEC và ETEC}

Kết quả khảo sát sự hiện diện của 5 gene betalactamase trên 59 chủng EHEC và ETEC thu được được trình bày ở Bảng 6 . Tỷ lệ hiện diện của 4 gene (blaampC, blaTEM, blaSHV, blaCTX-M1) không có sự khác biệt về mặt thống kê giữa các chủng thuộc nhóm EHEC và ETEC $(\mathrm{P}>0,05)$. Gene blaCMY không được tìm thấy trên tất cả các chủng EHEC và ETEC.
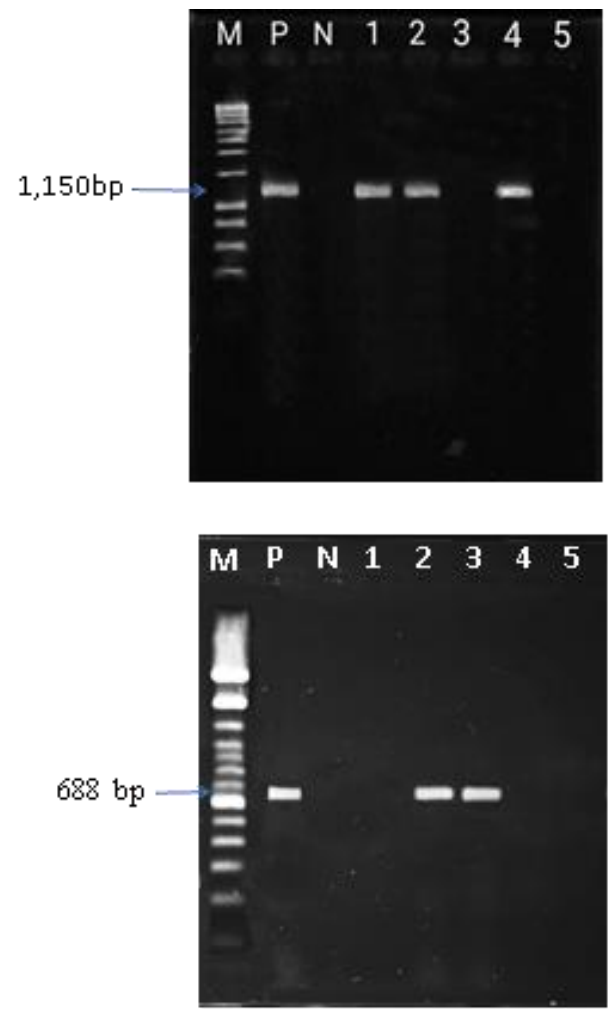

Hình 1. Kết quả điện di sản phẩm PCR xác định sự hiện diện của một số gene beta-lactamase trên vi khuẩn EHEC và ETEC

M: ladder 100 bp đối với (a), (c), (d) và ladder 200 bp đối với (b); P: đối chứng duơng; N: đối chứng âm

(a) Gene blaampC (191 bp): giếng 1, 5 (duong tính), giếng 2, 3, 4 (âm tính)

(b) Gene blaTEM (1.150 bp): giếng 1, 2, 4 (duoong tính), giếng 3, 5 (âm tính)

(c) Gene blaSHV (768 bp): giếng 1, 2, 3 (duơng tính), giếng 4, 5 (âm tính)

(d) Gene blaCTX-M1 (688 bp): giếng 2, 3 (duơng tính), giếng 1, 4, 5 (âm tính) 
Bảng 6. Sự hiện diện của gene đề kháng kháng sinh nhóm beta-lactam trên vi khuẩn EHEC và ETEC

\begin{tabular}{|c|c|c|c|c|}
\hline \multirow{2}{*}{ Gene } & \multicolumn{2}{|c|}{ Chủng EHEC $(n=21)$} & \multicolumn{2}{|c|}{ Chủng ETEC $(n=38)$} \\
\hline & Số chủng dương tính & Tỷ lệ (\%) & Số chủng dương tính & Tỷ lệ (\%) \\
\hline blaampC & 12 & 57,14 & 16 & 42,11 \\
\hline blaTEM & 2 & 9,52 & 7 & 18,42 \\
\hline blaSHV & 1 & 4,76 & 1 & 2,63 \\
\hline blaCTX-MI & 1 & 4,76 & 3 & 7,89 \\
\hline \multirow[t]{2}{*}{ blacMY } & 0 & 0,00 & 0 & 0,00 \\
\hline & & $(P<0,01)$ & & $(P<0,01)$ \\
\hline
\end{tabular}

Các nghiên cứu đã ghi nhận enzyme được tạo ra từ các gene blaampC, blaSHV, blaTEM, blaCTX và blaCMY có khả năng thủy phân các kháng sinh thuộc các thế hệ cephalosporin, cũng như các kháng sinh nhóm penicillin (al Naiemi et al., 2006; Paterson \& Bonomo, 2005; Pehlivanoglu et al., 2016). Trong nghiên cứu này, trên các chủng EHEC, gene blaampC xuất hiện với tỷ lệ cao nhất $(57,14 \%)$, tiếp đến là blaTEM $(9,52 \%)$ và blaSHV, blaCTX-M1 là thấp nhất với 4,76\% (Bảng 6). Sự hiện diện của các gene beta-lactamase ở mức độ trung bình (blaampC), và mức độ thấp (blaTEM, blaSHV, blaCTX-M1) có thể là nguyên nhân dẫn đến tình trạng đề kháng còn ở tỷ lệ trung bình hoặc thấp của EHEC đối với các kháng sinh thuộc nhóm penicillin và cephalosporin như ampicillin $(61,9 \%)$, ceftazidime $(33,33 \%)$ và cefuroxime $(15,25 \%)$. Nghiên cứu của Bùi Thị Ba và ctv. (2012) tại một số tỉnh Nam Trung Bộ cho thấy có $64,70 \%$ chủng vi khuẩn EHEC O157:H7 phân lập từ trâu bò khoẻ mạnh có khả năng mang ít nhất một loại gene betalactamase. Trong đó, gene blaTEM $(64,70 \%)$ xuất hiện với tỷ lệ cao nhất, kế đến là blaSHV và blaCMY $(11,76 \%)$. Nghiên cứu tại Nam Phi cho thấy các chủng EHEC đề kháng với ampicillin, amoxicillin được phân lập trên bò có sự hiện diện của các gene blaampC (90,00\%), blaCMY (70,00\%), blaCTX$M(65,00 \%)$ và blaTEM $(27,00 \%)$ (Iweriebor et al., 2015).

Đối với các chủng ETEC, gene blaampC cũng chiếm tỉ lệ cao nhất $(42,11 \%)$, kế đến là blaTEM $(18,42 \%)$, blaCTX-M1 $(7,89 \%)$ và thấp nhất là blaSHV với 2,63\% (Bảng 6). Trong nghiên cứu này, các chủng ETEC đề kháng khá thấp với các kháng sinh nhóm beta-lactam với tỷ lệ 7,89\%-31,58\% (Bảng 4). Như vậy, kết quả phân tích sự hiện diện của các gene beta-lactamase này trên ETEC được phân lập trên bò cho thấy sự tương đồng với kết quả biểu hiện trên kháng sinh đồ. Nghiên cứu của Lý Thị Liên Khai và ctv. (2015) ghi nhận các chủng ETEC phân lập trên heo tại tỉnh Vĩnh Long và Đồng Tháp đều mang gene blaTEM. Điều này cho thấy gene blaTEM có thể hiện diện phổ biến trên các chủng ETEC ở các đối tượng vật nuôi khác nhau.

Từ kết quả kiểm tra tỷ lệ hiện diện của các gene beta-lactamase của 59 chủng EHEC và ETEC bằng phương pháp PCR, các kiểu hình ghép gene đề kháng được thể hiện qua Bảng 7.

\section{Bảng 7. Kiểu hình kết hợp gene đề kháng kháng sinh nhóm beta-lactam của EHEC và ETEC (n=59)}

\begin{tabular}{llrrr}
\hline Số lượng gene & Kiểu hình ghép gene & Số kiểu ghép gene & Số chủng & Tỷ lệ $(\%)$ \\
\hline \multirow{2}{*}{ blaampC+ blaTEM } & 3 & 6 & 10,17 \\
& blaampC+blaCTX-M1 & & 1 & 1,69 \\
& blaTEM+blaCTX-M1 & & 1 & 1,69 \\
\hline \multirow{2}{*}{ Tổng } & & 3 & 8 & $(P<0,05)$ \\
& & & & 13,56 \\
\hline
\end{tabular}

Trong số 59 chủng EHEC và ETEC, có 8 chủng vi khuẩn $(13,56 \%)$ mang hai loại gene betalactamase với 3 kiểu hình kết hợp gene. Trong đó, kiểu hình kết hợp gene blaampC+blaTEM xuất hiện phổ biến nhất $(10,17 \%)$, kế đến là blaampC+blaCTX-M1 và blaTEM+blaCTX-M1 với tỷ lệ 1,69\% (Bảng 7). Gene blaampC xuất hiện nhiều nhất trong tổng số các chủng có kiểu hình kết hợp gene được khảo sát (7/8 chủng). Hầu hết các hiện tượng đa kháng do sự kết hợp các yếu tố di truyền di động như plasmid, transpose, integrin... góp phần phát tán các gene kháng kháng sinh (Braford, 2001; Carattoli, 2009). Hơn nữa, một chủng vi khuẩn có thể mang gene mã hóa đồng thời CTX-M, TEM và SHV hoặc CTX-M và $\mathrm{ampC}$, dẫn đến đa dạng kiểu hình đa kháng kháng sinh (Bradford, 2001; Escobar-Paramo et al., 2006). Tamang et al. (2013) xác định tỷ lệ và đặc điểm của CTX-M trên các chủng $E$. coli sinh ESBL cho thấy CTX-M trên các chủng phân lập từ mẫu phân bò là 0,2\%; loại CTX-M chiếm ưu thế nhất được xác định là $\mathrm{CTX}-\mathrm{M}-14$, tiếp theo là $\mathrm{CTX}-\mathrm{M}-15$, và gene 
blaTEM-1 thường kết hợp với blaCTX-M trên các chủng $E$. coli phân lập. Trong nghiên cứu này, tỷ lệ và kiểu hình kết hợp của các gene beta-lactamase còn thấp $(13,56 \%)$. Tuy nhiên, điều này vẫn cho thấy mối nguy cơ các chủng EHEC và ETEC phân lập trên bò có khả năng đề kháng với nhiều kháng sinh thuộc nhóm beta-lactam dùng trong điều trị bệnh do $E$. coli gây ra.

\section{KẾT LUậN}

Vi khuẩn EHEC và ETEC phân lập được trên bò còn nhạy cảm với hầu hết các kháng sinh được khảo sát. Tuy nhiên, EHEC đã có sự đề kháng với tỷ lệ khá cao đối với colistin và ampicillin. Các chủng EHEC và ETEC đề kháng kháng sinh này hình thành nên nhiều kiểu hình đa kháng (13-14 kiểu hình) và đề kháng từ 2 đến 8 loại kháng sinh, trong đó ampicillin hiện diện trong hầu hết các kiểu hình đa kháng. Ngoài ra, trong các gene beta-lactamase khảo sát, gene blaampC và blaTEM hiện diện chiếm tỷ lệ cao nhất trên các chủng EHEC và ETEC được phân lập từ bò. Kết quả nghiên cứu cho thấy các chủng EHEC và ETEC đa kháng kháng sinh này có thể là mối nguy cơ tiềm ẩn tác động đến hiệu quả phòng trị bệnh do $E$. coli trên bò tại tỉnh Bến Tre.

\section{LỜI CẢM TẠ}

Đề tài này được thực hiện dưới sự hỗ trợ thông qua Đề tài nghiên cứu khoa học cấp Trường dành cho cán bộ của Trường Đại học Cần Thơ.

\section{TÀI LIỆU THAM KHẢO}

al Naiemi, N., Bart, A., de Jong, M.D., Vandenbroucke-Grauls, C.M., Rietra, P.J., DebetsOssenkopp, Y.J., Wever, P.C., Spanjaard, L., Bos, A.J., \& Duim, B. (2006). Widely distributed and predominant CTX-M extended-spectrum betalactamases in Amsterdam, The Netherlands. Journal of Clinical Microbiology, 44(8), 30123014. https://doi.org/10.1128/JCM.01112-06

Ali, T., Zhang, L., Shahid, M., Zhang, S., Liu, G., Gao, J., Han, B., \& Rahman, S.U. (2016). ESBLProducing Escherichia coli from cows suffering mastitis in China contain clinical class 1 integrons with CTX-M linked to ISCR 1. Frontiers in Microbiology, 7, 1931.

https://doi.org/10.3389/fmicb.2016.01931

Armstrong, G.L., Hollingsworth, J., \& Morris, J.G.J. (1996). Emerging foodborne pathogens: Escherichia coli $\mathrm{O} 157: \mathrm{H} 7$ as a model of entry of a new pathogen into the food supply of the developed world. Epidemiologic Reviews, 18(1), 29-51. https://doi.org/10.1093/oxfordjournals.epirev.a0 17914
Ball, T.A., Monte, D.F., Aidara-Kane, A., MatheuAlvarez, J., Ru,H., Thakur, S., Horovitz, J., Ejobi, F., Lacher, D.W., \& Fedorka-Cray, P.J. (2019). Phenotypic and genotypic characterization of Escherichia coli and Salmonella enterica from dairy cattle farms in the Wakiso District, Uganda: A cross-sectional study. Foodborne Pathogens and Disease, 16(1), 54-59. https://doi.org/10.1089/fpd.2018.2528

Bauer, A.W., Kirby, W.M.M., Sherris, J.C., \& Turck, M. (1966). Antibiotic susceptibility testing by standardized single disk method. American Journal of Clinical Pathology, 45(4), 493-49. https://doi.org/10.1093/ajcp/45.4_ts.493

Bradford, P.A. (2001). Extended-Spectrum- $\beta-$ lactamases in the 21 st century: characterization, epidemiology, and detection of this important resistance threat. Clinical Microbiology Reviews, 14(4), 933-951. https://doi.org/10.1128/CMR.14.4.933-951.2001

Bùi Thị Ba, Đào Hoài Thu, Võ Thành Thìn, Đặng Văn Tuấn, Đỗ Văn Tấn, \& Vũ Khắc Hùng. (2012). Xác định một số gen kháng kháng sinh của vi khuẩn Escherichia coli $\mathrm{O} 157$ : $\mathrm{H} 7$ phân lập từ trâu bò khỏe mạnh tại một số tỉnh Nam Trung Bộ. Tạp chí Khoa hoc kỹ thuật Thú y, 19(6), 52-58.

Carattoli, A. (2009). Resistance plasmid families in Enterobacteriaceae. Antimicrobial Agents and Chemotherapy, 53(6), 2227-2238. https://doi.org/10.1128/AAC.01707-08

Caroff, N., Espaze, E., Berard, I., Richet, H., \& Reynaud, A. (1999). Mutations in the ampC promoter of Escherichia coli isolates resistant to oxyiminocephalosporins without extended spectrum $\beta$-lactamase production. FEMS Microbiology Letters, 173(2), 459-465. https://doi.org/10.1016/S0378-1097(99)00111-1

Clinical and Laboratory Standards Institute-CLSI. (2019). Performance Standard for Antimicrobial Susceptibility Testing M100S (29th ed). Clinical and Laboratory Standard Institute, Wayne, PA, USA.

Dallenne, C., Costa, A.D., Decré, D., Favier, C., \& Arlet, G. (2010). Development of a set of multiplex PCR assays for the detection of genes encoding important $\beta$-lactamases in Enterobacteriaceae. Journal of Antimicrobial Chemotherapy, 65(3), 490-495. https://doi.org/10.1093/jac/dkp498

Eckert, C., Gautier, V., Saladin-Allard, M., Hidri, N., Verdet, C., \& Ould-Hocine, Z. (2004). Dissemination of CTX-M-type beta-lactamases among clinical isolates of Enterobacteriaceae in Paris, France. Antimicrobial Agents and Chemotherapy, 48(4), 1249-1955. https://doi.org/10.1128/AAC.48.4.12491255.2004 
Escobar-Paramo, P., Menac'h, L.A., \& Gall, L.T. (2006). Identification of forces shaping the commensal Escherichia coli genetic structure by comparing animal and human isolates. Environmental Microbiology Reports, 8(11), 1975-1984. https://doi.org/10.1111/j.14622920.2006.01077.x

Ibrahim, D.R., Dodd, D.E., Stekel, D.J., Ramsden, S.J., \& Hobman, J.L. (2016). Multidrug resistant, extended spectrum $\beta$-lactamase (ESBL)producing Escherichia coli isolate from a daily farm. FEMS Microbiology Ecology, 92(4). https://doi.org/10.1093/femsec/fiw013

Iweriebor, B.C., Iwu, C.J., Obi, L.C., Nwodo, U.U., \& Okoh, A.I. (2015). Multiple antibiotic resistances among Shiga toxin producing Escherichia coli $\mathrm{O} 157$ in feces of dairy cattle farms in Eastern Cape of South Africa. BMC Microbiology, 15. https://doi.org/10.1186/s12866-015-0553-y

Jouini, A., Vinué, L., Slama, K.B., Saenz, Y., Klibi, N., Hammami, S., Boudabous, A., \& Torres, C. (2007). Characterization of CTX-M and SHV extended-spectrum $\beta$-lactamases and associated resistance genes in Escherichia coli strains of food samples in Tunisia. Journal of Antimicrobial Chemotherapy, 60(5), 1137-1141. https://doi.org/10.1093/jac/dkm316

Liu, B., \& Pop, M. (2009). ARDB - antibiotic resistance genes database. Nucleic Acids Research, 37(1), 443-447. https://doi.org/10.1093/nar/gkn656

Lý Thị Liên Khai, Nguyễn Thị Hạnh Chi, \& Nguyễn Thanh Lãm. (2015). Khảo sát tỷ lệ nhiễm và xác định gene kháng kháng sinh của Enterotoxigenic Escherichia coli trên heo con tiêu chảy tại tỉnh Vĩnh Long và Đồng Tháp. Tạp chi Khoa học Truòng Đại học Cần Tho, 39, 7-17.

Montso, K.P., Dlamini, S.B., Kumar, A., \& Ateba, C.N. (2019). Antimicrobial resistance factors of Extended-Spectrum Beta-Lactamase producing Escherichia coli and Klebsiella pneumoniae isolated from cattle farms and raw beef in NorthWest Province, South Africa. Biomed Research International, 2019, 4318306. https://doi.org/10.1155/2019/4318306

Nguyễn Khánh Thuận \& Lý Thị Liên Khai. (2020). Sự hiện diện các gene độc lực và tính đề kháng kháng sinh của vi khuẩn Escherichia coli $\mathrm{O} 157$ : $\mathrm{H} 7 / \mathrm{H}$ - phân lập từ bò tại Đồng bằng sông Cửu Long. Tạp chí Khoa học Truờng Đại hoc Cần Tho, 56(6B), 112-118. https://doi.org/10.22144/ctu.jvn.2020.149

Nguyễn Xuân Hòa, Phạm Đăng Tuấn, Trần Lê Hoàn, Lê Quốc Việt, Thượng Thị Thanh Lễ, Phan Vũ Hải \& Trần Quang Vui. (2020). Độc lực và tính mẫn cảm kháng sinh của vi khuẩn Escherichia coli phân lập từ bê sữa bị bệnh tiêu chảy. Tạp chí Khoa hoc kỹ thuật Thú y, 17(7), 24-30.

Nguyen, N.T., Nguyen, H.M., Nguyen, C.V., Nguyen, T.V., Nguyen, M.T., Thai, H.Q., Ho, M.H., Thwaites, G., Ngo, H.T., Baker, S., \& Carrique-Mas, J. (2016). Use of colistin and other critial antimicrobials on pig and chicken farm in Southern Vietnam and its association with resistance in commensal Esscherichia coli bacteria. Applied and Environmental Microbiology, 82(13), 3727-3735. https://doi.org/10.1128/AEM.00337-16

Nguyen, Y., \& Sperandio, V. (2012). Enterohemorrhagic E. coli (EHEC) pathogenesis. Frontiers in cellular and infection microbiology, 2, 90. https://doi.org/10.3389/fcimb.2012.00090

Partridge, S.R. (2011). Analysis of antibiotic resistance regions in Gram-negative bacteria. FEMS Microbiology Reviews, 35(5), 820-855. https://doi.org/10.1111/j.15746976.2011.00277.x

Paterson, D.L., \& Bonomo, R.A. (2005). Extended spectrum beta-lactamase: a clinical update. Clinical Microbiology Reviews, 18(4), 657-686. https://doi.org/10.1128/CMR.18.4.657-686.2005

Pehlivanoglu, F., Turutoglu, H., Ozturk, D., \& Yardimci, H. (2016). Molecular characterization of ESBL-Producing Escherichia coli isolated from healthy cattle and sheep. Acta VeterinariaBeograd, 66(4), 520-533. https://doi.org/10.1515/acve-2016-0045

Poirel, L., Madec, J.Y., Lupo, A., Schink, A.K., Kieffer, N., Nordmann, P., \& Schwarz, S. (2018). Antimicrobial Resistance in Escherichia coli. Microbiology Spectrum, 6(4). https://doi.org/10.1128/microbiolspec.ARBA0026-2017

Soumet, C., Ermel, G., Fach, P., \& Colin, P. (1994). Evaluation of different DNA extraction procedures for the detection of Salmonella from chicken products by polymerase chain reaction. Letters in Applied Microbiology, 19(5), 294-298. https://doi.org/10.1111/j.1472765X.1994.tb00458.x

Tamang, M.D., Nam, H.M., Kim, S.R., Chae, M.H., Jang, G.C., Jung, S.C., \& Lim, S.K. (2013). Prevalence and molecular characterization of CTX-M $\beta$-lactamase-producing Escherichia coli isolated from healthy swine and cattle.

Foodborne Pathogens and Disease, 10(1), 13-20. https://doi.org/10.1089/fpd.2012.1245

Van, T.T., Chin, J., Chapman, T., Tran, L.T., \& Coloe, P.J. (2008). Safety of raw meat and shellfish in Vietnam: an analysis of Escherichia coli isolations for antibiotic resistance and virulence genes. International Journal of Food 
Microbiology, 124(3), 217-223.

https://doi.org/10.1016/j.ijfoodmicro.2008.03.029

Võ Văn Ninh. (2001). Sụ đề kháng của vi trùng với kháng sinh. Trong Võ Văn Ninh (Chủ biên). Kháng sinh trong thú y (trang 17-21). Nhà xuất bản Trẻ.

Yamamoto, S., Iwabuchi, E., Hasegawa, M., Esakim, H., Muramatsu, M., Hirayama, N., \& Hirai, K. (2013). Prevalence and molecular epidemiological characterization of antimicrobial-resistant Escherichia coli isolates from Japanese black beef cattle. Journal of Food Protection, 76(3), 394-404.

https://doi.org/10.4315/0362-028X.JFP-12-273

Yamamoto, S., Nakano, M., Kitagawa, W., Tanaka, M., Sone, T., Hirai, K., \& Asano, K. (2014). Characterization of multi-antibiotic-resistant Escherichia coli isolated from beef cattle in Japan. Microbes and Environments, 29(2), 136144. https://doi.org/10.1264/jsme2.ME13173 